DIMENSI, VOL. 7, NO. $1: 1-9$

MARET 2018

ISSN: 2085-9996

\title{
ANALISIS PENDEKATAN ITM (ILMU TEKNOLOGI MASYARAKAT) DI DALAM MENGATASI PEMBELAJARAN IPS PADA PESERTA DIDIK
}

\section{APPROACH ANAL YSIS OF ITM (SCIENTIFIC TECHNOLOGY SCIENCE) TO MANAGE THE SOCIAL SCIENCE FOR THE STUDENTS}

\author{
Anastasia Dewi Anggraeni \\ Pendidikan Bahasa Inggris, Universitas Indraprasta PGRI \\ angelinanasta@gmail.com
}

\begin{abstract}
Abstrak
Dalam segi hasil atau dampak pendidikan Ilmu Pengetahuan Sosial atau IPS terhadap kehidupan bermasyarakat, masih belum begitu nampak. Perwujudan nilai-nilai sosial yang dikembangkan di sekolah belum nampak dalam kehidupan sehari-hari, keterampilan sosial para sosial para lulusan pendidikan dasar khususnya masih memprihatinkan, partisipasi dalam berbagai kegiatan kemasyarakatan semakin menyusut. Model pembelajaran saat ini juga lebih menekankan pada aspek kebutuhan formal dibanding kebutuhan real siswa sehingga proses pembelajaran terkesan sebagai pekerjaan administratif dan belum mengembangkan potensi anak secara optimal. Berdasarkan permasalahan pembelajaran IPS di atas, maka diperlukan model pembelajaran dengan pendekatan ITM (Ilmu Teknologi Masyarakat, sebuah pendekatan untuk mencapai tujuan pembelajaran yang berkaitan langsung dengan lingkungan nyata dengan cara melibatkan peran aktif peserta didik dalam mencari informasi untuk memecahkan masalah yang ditemukan dalam kehidupan kesehariannya.
\end{abstract}

Katakunci: analisis, pendekatan ITM, pembelajaran IPS, peserta didik

\begin{abstract}
In terms of results or impact of education Social Science or Social Studies on social life, still not so visible. The embodiment of social values developed in schools has not been seen in everyday life, social skills of the social graduates of primary education in particular are still apprehensive, participation in various social activities is shrinking. The current learning model is also more emphasized on the aspect of formal needs than the real needs of students so that the learning process impressed as an administrative work and has not developed the potential of children optimally. Based on the problem of IPS learning above, it is necessary to model the learning with the approach of ITM (Science of Community Technology, an approach to achieve learning objectives directly related to the real environment by involving the active role of learners in seeking information to solve problems found in their daily lives.
\end{abstract}

Keywords: analysis, the approach of ITM (science of community technology, learning social science education, learnerse

\section{PENDAHULUAN}

Pendidikan IPS merupakan mata pelajaran dengan bidang kajian yang mendudukkan konsep dasar berbagai ilmu sosial yang disusun melalui pendekatan pendidikan dan 
pertimbangan psikologis, dan sangat dibutuhkan pada kehidupan setiap siswa mulai dari tingkat SD, SMP, untuk membekali dan mempersiapkan peserta didik dalam melanjutkan pendidikkan yang lebih tinggi. Pendidikkan IPS bukanlah suatu program pendidikan disiplin ilmu tetapi suatu kajian tentang masalah-masalah sosial yang dikemas dengan mempertimbangkan factor psikologi perkembangan peserta didik dan waktu kulikuler untuk program pendidikan.

Melalui pendidikan IPS di sekolah, diharapkan dapat member wawasan dan pengetahuan tentang konsep dasar ilmu social dan humaniora, agar memiliki kepekaan dan kesadaran terhadap masalah sosial di lingkungannya, serta mampu memecahkan masalah social dengan baik, yang pada akhirnya siswa belajar IPS dapat terbina menjadi warga Negara yang baik dan bertanggung jawab.

Mata pelajaran IPS bertujuan mengembangkan potensi peserta didik agar peka terhadap masalah sosial yang terjadi di masyarakat. Pendidikan IPS sudah lama dikembangkan dan dilaksanakan dalam kurikulum-kurikulum di Indonesia, khususnya pada jenjang pendidikan dasar dan menengah.

Pendidikan ini tidak dapat disangkal telah membawa beberapa hasil, walaupun belum optimal. Secara umum penguasaan pengetahuan sosial atau kewarganegaraan lulusan pendidikan dasar relatif cukup, tetapi penguasaan nilai dalam arti penerapan nilai, keterampilan sosial dan partisipasi sosial hasilnya belum menggembirakan. Kelemahan tersebut sudah tertentu terkait atau dilatarbelakangi oleh banyak hal, terutama proses pendidikan atau pembelajarannya, kurikulum, para pengelola dan pelaksananya serta faktorfaktor yang berpengaruh lainnya.

Berhasil atau tidaknya pendidikan terletak pada berbagai komponen dalam proses pendidikan guru. Seiring belum berhasilnya guru dalam mengajar IPS terpadu dapat dipengaruhi oleh beberapa factor diantaranya kurangnya kemampuan guru dalam menguasai materi IPS terpadu, kurang variasi metode yang digunakan, guru kurang memanfaatkan media pembelajaran dan kurangnya kesiapan guru dalam perangkat pembelajaran. Pembelajaran terpadu merupakan suatu kemasan interdisiplinear atau bentuk reduksi antar disiplin ilmu yang 
serumpun dengan memperhatikan perkembangan-perkembangan peserta didik dalam rangka pemberian pemahaman utuh dan komprehensif terhadap suatu permasalahan atau fenomena.

Beberapa temuan penelitian dan pengamatan ahli memperkuat kesimpulan tersebut. Dalam segi hasil atau dampak pendidikan Ilmu Pengetahuan Sosial atau IPS terhadap kehidupan bermasyarakat, masih belum begitu nampak. Perwujudan nilai-nilai sosial yang dikembangkan di sekolah belum nampak dalam kehidupan sehari-hari, keterampilan sosial para sosial para lulusan pendidikan dasar khususnya masih memprihatinkan, partisipasi dalam berbagai kegiatan kemasyarakatan semakin menyusut.

Berkenaan dengan kurikulum dan rancangan pembelajaran IPS, beberapa penelitian memberi gambaran tentang kondisi tersebut. Hasil penelitian Balitbang, Depdikbud tahun 1999 menyebutkan bahwa "Kurikulum 1994 tidak disusun berdasarkan basic competencies melainkan pada materi, sehingga dalam kurikulumnya banyak memuat konsepkonsep teoritis” (Boediono, 1999).

Dalam implementasi materi (Muchtar, 1991)menemukan IPS lebih menekankan aspek pengetahuan, berpusat pada guru, mengarahkan bahan berupa informasi yang tidak mengembangkan berpikir nilai serta hanya membentuk budaya menghafal dan bukan berpikir kritis. Dalam pelaksanaan, (Permana, 1998) menilai pembelajaran IPS sangat menjemukan karena penyajiannya bersifat monoton dan ekspositoris sehingga siswa kurang antusias dan mengakibatkan pelajaran kurang menarik padahal menurut guru IPS wajib berusaha secara optimum merebut minat siswa karena minat merupakan modal utama untuk keberhasilan pembelajaran IPS.

Selanjutnya Como dan Snow (Nursid, 1996) menilai bahwa model pembelajaran IPS yang diimplementasikan saat ini masih bersifat konvensional sehingga siswa sulit memperoleh pelayanan secara optimal. Dengan pembelajaran seperti itu maka perbedaan individual siswa di kelas tidak dapat terakomodasi sehingga sulit tercapai tujuan-tujuan spesifik pembelajaran terutama bagi siswa berkemampuan rendah. Model pembelajaran saat ini juga lebih menekankan pada aspek kebutuhan formal dibanding kebutuhan real siswa sehingga proses pembelajaran terkesan sebagai pekerjaan administratif dan belum mengembangkan potensi anak secara optimal. 
Berdasarkan hal-hal di atas nampak, bahwa pada satu sisi betapa pentingnya peranan pendidikan IPS dalam mengembangkan pengetahuan, nilai. Sikap, dan keterampilan sosial agar siswa menjadi warga masyarakat, bangsa dan negara Indonesia yang baik namun di pihak lain masih banyak masalah-masalah tersebut diperlukan penelitian berkaitan dengan pembelajaran IPS. Salah satu upaya yang memadai untuk itu adalah dengan melakukan model pembelajaran.

\section{METODOLOGI}

Metode penelitian yang digunakan penelitian adalah metode deskriptif kualitatif. Menurut (Sudaryanto, 1993), metode kualitatif mengacu pada penelitian yang berkaitan dengan data penelitian yang tidak berupa angka, tetapi berupa kata atau frasa. Analisis deskriptif merupakan proses menggambarkan fenomena yang terjadi saat ini dengan menggunakan prosedur ilmiah untuk menjawab masalah aktual. Analisis deskriptif dipilih untuk memperoleh gambaran yang sistematis mengenai data-data penelitian yang kemudian dikelompokkan menurut pola tertentu. Penelitian ini menggunakan metode deskriptif karena menitikberatkan kepada deskripsi tentang langkah-langkah penerapan pendekatan ITM (Ilmu Teknologi Masyarakat).

Peneliti mengumpulkan materi-materi pembelajaran IPS yang sesuai kurikulum nasional 2013. Peneliti menetapkan standar tersebut dengan harapan ada banyak data yang bisa dijaring.

Penelitian ini menggunakan teknik analisis isi (content analysis). Menurut Harold D. Lasswell (Kholil, 2006) pengertian teknik analisis isi (content analysis) adalah penelitian yang bersifat pembahasan mendalam terhadap isi suatu informasi tertulis atau tercetak dalam media massa.Analisis isi dapat digunakan untuk menganalisis semua bentuk komunikasi. Baik surat kabar, berita radio, iklan televisi maupun semua bahan-bahan dokumentasi yang lain.

Setelah mendapatkan data yang diinginkan, langkah selanjutnya adalah menganalisis data. Dalam menganalisa tema materi, penulis melakukan beberapa tahapan alisis. Pertama, data yang sudah terkumpul kemudian diidentifikasi dan dikelompokkan berdasarkan kategori yang ditentukan. Setelah itu, peneliti menganalisis proses isi tema materi dengan pendekatan ITM. 


\section{PEMBAHASAN}

Tabel 1 Analisa dan Identifikasi Materi IPS Kelas 7 Melalui Pendekatan ITM

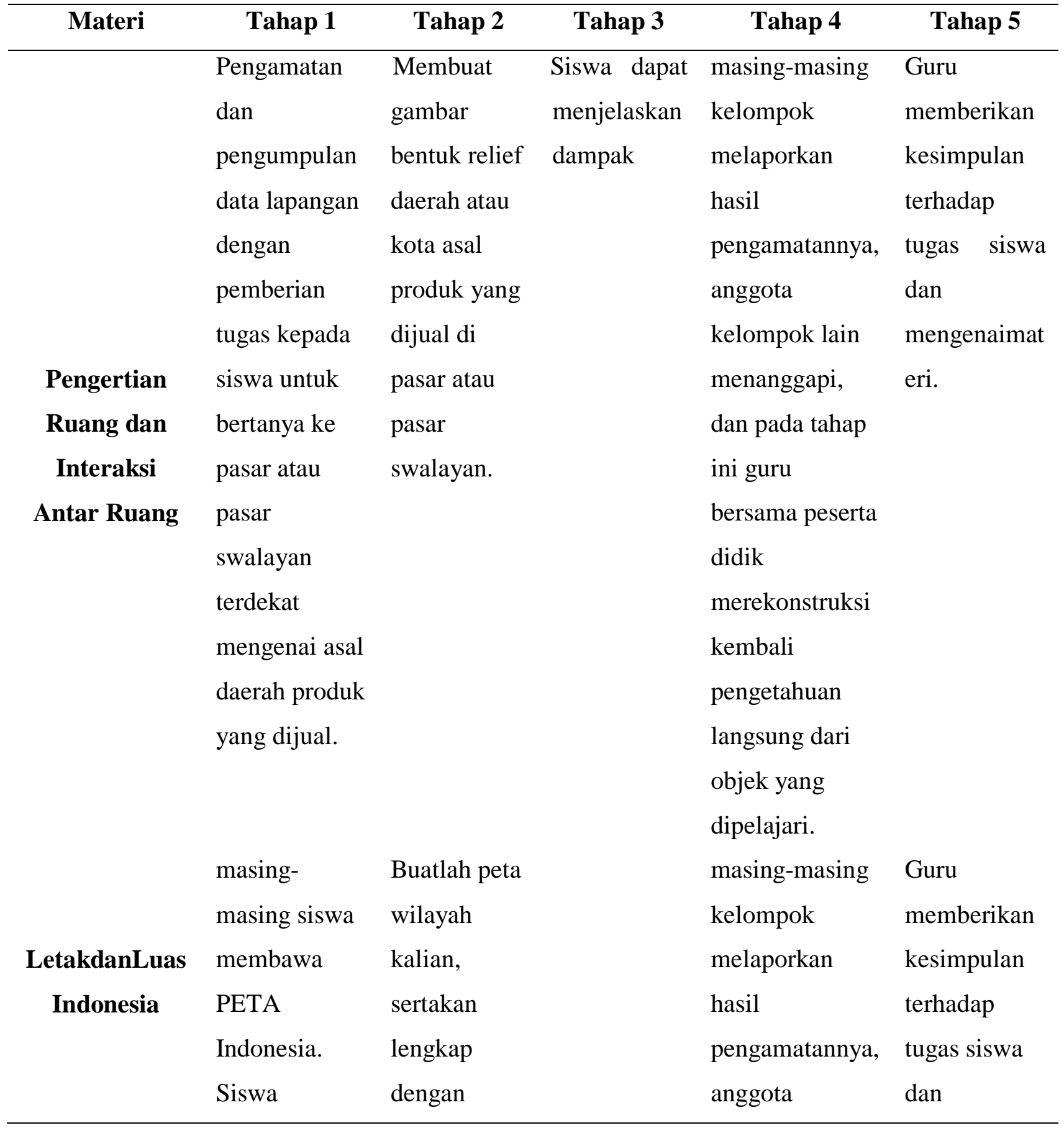




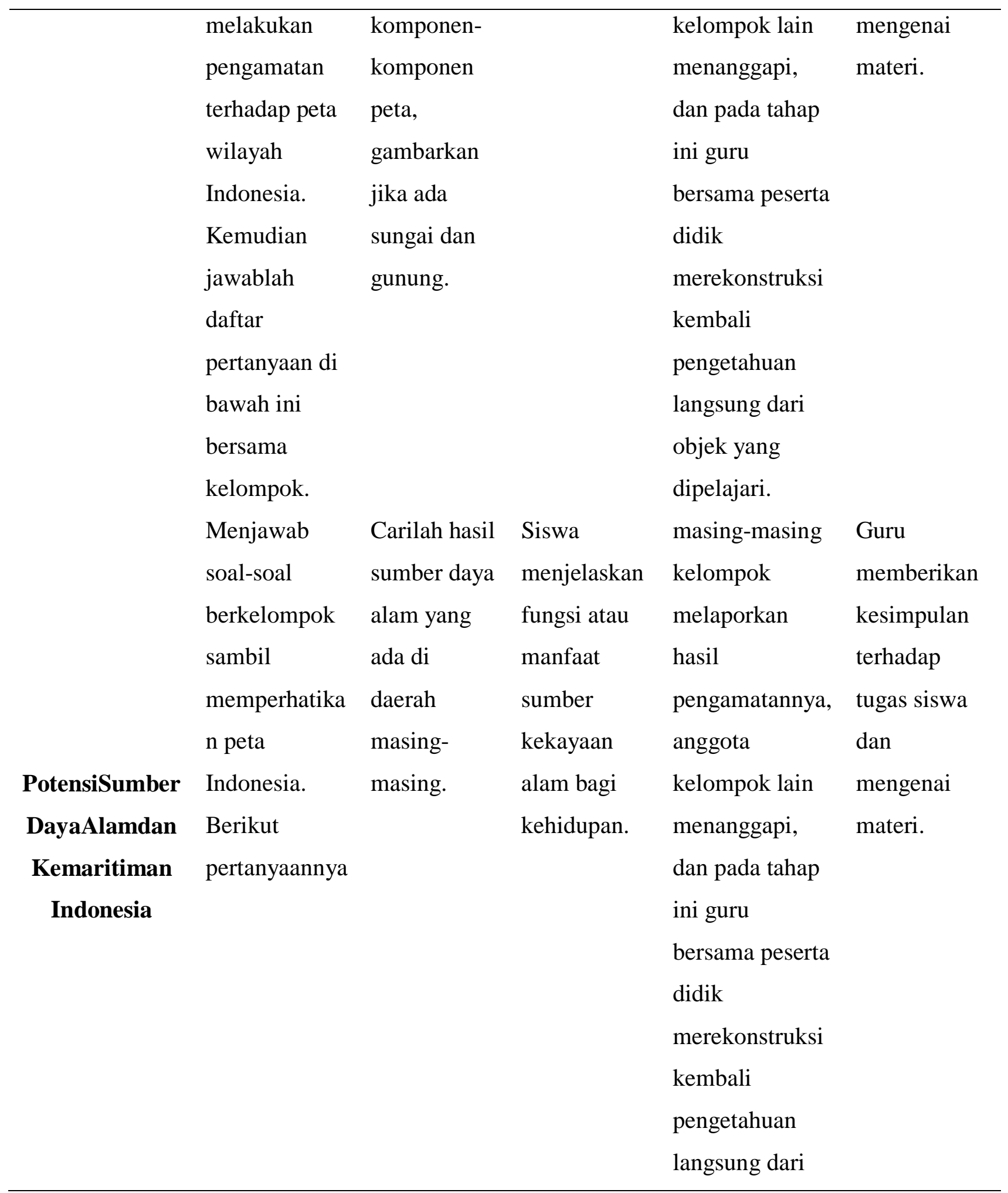




\begin{tabular}{|c|c|c|c|c|c|}
\hline & & & & objek yang & \\
\hline & Aktivitas & Buat & masing- & $\begin{array}{l}\text { dipelajari. } \\
\text { masing-masing }\end{array}$ & Guru \\
\hline & kelompok & kelompok & masing & kelompok & memberikan \\
\hline & dengan & kemudian & kelompok & melaporkan & kesimpulan \\
\hline & menjawab & carilah data & mencari foto & hasil & terhadap \\
\hline & pertanyaan di & kependuduk & atau gambar & pengamatannya, & tugas siswa \\
\hline & bawah ini. & an di daerah & mengenai & anggota & dan \\
\hline & & tempat & rumah adat, & kelompok lain & mengenai \\
\hline & & tinggalmu & pakaian adat, & menanggapi, & materi. \\
\hline Gimaminainepe & & melalui & dan senjata & dan pada tahap & \\
\hline & & sumber & daerah di & ini guru & \\
\hline Mutinesid & & kantor & wilayah di & bersama peserta & \\
\hline & & kelurahan & Indonesia. & didik & \\
\hline & & atau internet. & Tempelkan & merekonstruksi & \\
\hline & & Berikut data & seperti & kembali & \\
\hline & & kependuduk & poster dan & pengetahuan & \\
\hline & & an yang & tempel di & langsung dari & \\
\hline & & harus dicari. & madding & objek yang & \\
\hline & & & sekolah. & dipelajari. & \\
\hline
\end{tabular}

Kedudukan kosep ilmu, teknologi dan masyarakat menjadi suatu yang ideal sebagai bahan yang dapat membantu para peserta didik untuk memahami dan dapat menjelaskan konsep-konsep energi, polusi, lingkungan, sumber daya alam, air, dan lain-lain yang relevan dengan dinamika ilmu, teknologi dan masyarakat.

Sehubungan dengan itu Remy, 1990 (dalam Udin. S. Winataputra, dkk. 2007:8.6) berpendapat bahwa penggunaan langkah-langkah pengambilan keputusan yang sistematis dalam mempelajari isu-isu ilmu, teknologi dan masyarakat dalam pembelajaran IPS dapat 
membantu mengembangkan intelektual peserta didik, kemampuan memecahkan masalah dan kemampuan berfikir dalam mengambil keputusan secara fleksibel dan terorganisasi. Kurikulum IPS merupakan sarana di mana peserta didik dapat belajar tentang, masyarakat serta akibat-akibat yang ditimbulkan dari ilmu dan teknologi.

Pendekatan ITM (Ilmu, Teknologi, dan Masyarakat) atau juga disebut STS (ScienceTechnology-Society) muncul menjadi sebuah pilihan jawaban atas kritik terhadap pengajaran Ilmu Pengetahuan Sosial yang bersifat tradisional (texbook), yakni berkisar masih pada pengajaran tentang fakta-fakta dan teori-teori tanpa menghubungkannya dengan dunia nyata yang integral. ITM dikembangkan kemudian sebagai sebuah pendekatan guna mencapai tujuan pembelajaran yang berkaitan langsung dengan lingkungan nyata dengan cara melibatkan peran aktif peserta didik dalam mencari informasi untuk meemcahkan masalah yang ditemukan dalam kehidupan kesehariannya.

Dalam kegiatan pembelajaran tersebut peserta didik menjadi lebih aktif dalam menggali permasalahan berdasarkan pada pengalaman sendiri hingga mampu melahirkan kerangka pemecahan masalah dan tindakan yang dapat dilakukan secara nyata. Karena itu, pendekatan ITM dipandang dapat memberi kontribusi langsung terhadap misi pokok pembelajaran pengetahuan sosial, khusus dalam mempersiapkan warga negara agar memiliki kemampuan:

1) Memahami ilmu pengetahuan di masyarakat

2) Mengambil keputusan sebagai warga negara

3) Membuat hubungan antar pengetahuan

4) Mengingat sejarah perjuangan dan peradaban luhur bangsanya.

Pendekatan yang digunakan dalam pengajaran IPS untuk proses pembelajaran ITM adalah interdisipliner atau multidisipliner. Dalam Konsep Ilmu, Teknologi dan Masyarakat tidak luput dari dampak positif dan dampak negative sehingga mempengaruhi perkembangan dunia IPTEK. 


\section{KESIMPULAN}

Salah satu ciri yang paling penting dari warga Negara yang mempunyai perhatian terhadap lingkungan masyarakat yang serba kompleks, adalah kemampuan membuat kaitan antara hal yang nampaknya sederhana dengan cara mengungkapkan ciri-ciri tertentu sehingga menjadi bermakna. Apabila guru-guru IPS membelajarkan peserta didiknya menggunakan langkah- langkah yang sistematis dengan cara pemahaman isu-isu ilmu, teknologi dan masyarakat, hal ini dapat membantu peserta didik bagaimana cara menjelaskan keterkaitan antara bermacam-macam disiplin ilmu dengan IPS. Dengan demikian kemampuan memecahkan masalah tentang isu-isu ilmu, teknologi dan masyarakat dapat teratasi dengan baik. Demikian, beberapa konsep ilmu, teknologi, dan masyarakat (ITM) dapat memberikan konstribusi terhadap misi pokok IPS, khususnya dalam mempersiapkan warga Negara Indonesia yang melek ilmu pengetahuan dan banyak tahu tentang ilmu, teknologi dan sosial.

\section{REFERENSI}

Boediono, e. a. (1999). Penyempurnaan Kurikulum 1994 Berbasis Kemampuan ～Dasar: Laporan Awal. Jurnal Pendidikan dan Kebudayaan, $\quad$ 82-97.

Muchtar, S. (1991). Pengembangan Kemampuan Berpikir dan Nilai Dalam Pendidikan Ilmu Pengetahuan Sosial (Suatu Studi Sosial Budaya Pendidikan). Bandung: Disertasi Program Pasca Sarjana Universitas Pendidikan Indonesia.

Nurdin, S. (2001). Penerapan Model Pendekatan Aptitude Treatment Interaction (ATI) dalam Pembelajaran IPS di SD. (Disertasi). Bandung: PPs UPI: Tidak Diterbitkan.

Nursid, S. (1996). Manusia Dalam Konteks Sosial Budaya dan Lingkungan Hidup. Bandung: Alfabeta.

Permana, M. S. (1998). Strategi Belajar Mengajar. Jakarta: Depdikbud.

Sudaryanto. (1993). Metode dan Aneka Teknik Analisis Bahasa: Pengantar Penelitian Wahana Kebudayaan Secara Linguistik. Yogyakarta: Duta Wacana University Press. 